\title{
Sistema de Gestão da Qualidade do Laboratório de Gravimetria do Observatório Nacional
}

Olivia Woyames Pinto* - olivia@on.br

Mauro Andrade de Sousa

MCTI - Observatório Nacional

Copyright 2012, SBGf - Sociedade Brasileira de Geofísica

Este texto foi preparado para a apresentação no V Simpósio Brasileiro de Geofísica Salvador, 27 a 29 de novembro de 2012. Seu conteúdo foi revisado pelo Comitê Técnico do V SimBGf, mas não necessariamente representa a opinião da SBGf ou de seus associados. É proibida a reprodução total ou parcial deste material para propósitos comerciais sem prévia autorização da SBGf.

\section{Resumo}

A implantação do Sistema de Gestão da Qualidade no Laboratório de Gravimetria do Observatório Nacional é fundamentada na adequação à norma ABNT NBR ISO/IEC 17025:2005. Esta apresenta os princípios de gestão e técnicos a serem seguidos com o intuito de: i garantir o alto nível de qualidade das medições gravimétricas, ii a confiabilidade dos resultados encontrados, e iii demonstrar a competência do laboratório em realizar a grandeza gravidade. Adotado um SGQ baseado na norma 17025, todas as atividades profissionais no laboratório são compulsoriamente governadas por um conjunto de procedimentos técnicos e de gestão que devem ser seguidos à risca. $O$ documento principal do SGQ é o Manual da Qualidade que descreve a estrutura de funcionamento do laboratório e a sua política de qualidade, bem como refere todos os procedimentos de uso válido no laboratório.

\section{Introdução}

A norma ABNT NBR ISO/ IEC 17025:2005 descreve os requisitos gerais que os laboratórios de ensaio e de calibração devem atender se desejarem demostrar que são tecnicamente competentes na realização das grandezas que declaram capacidade. Tais requisitos aplicam-se igualmente tanto a laboratórios industriais como didáticos e científicos. A norma exige que os laboratórios implantem procedimentos para a garantia da qualidade de todas as etapas experimentais e de processamento necessárias à realização de um ensaio ou de uma calibração. A norma não especifica a maneira como esses procedimentos devem ser implantados, e cada laboratório é livre para escolher a forma que mais Ihe convém, observadas as exigências da norma. Entretanto, a Norma 17025:2005 exige que sejam estabelecidos controles de atendimento estrito de todos os procedimentos que o laboratório declara seguir.

O objetivo do Sistema de Gestão da Qualidade de um laboratório é o de gerenciar todas as atividades que possam afetar a qualidade da medição da grandeza realizada neste laboratório. O Sistema de Gestão da Qualidade é montado a partir da elaboração de procedimentos técnico-científicos e de gestão laboratorial propriamente documentados, i.e. assinados e controlados. Esta sistemática assegura a continuidade da metodologia utilizada pela equipe do laboratório em realizar a grandeza que declaram ter competência para medir, e sempre com a mesma qualidade. Cada um dos procedimentos adotados deve descrever a realização padronizada e adequada de uma atividade laboratorial, descrevendo o registro adequado dessa atividade. $O$ Manual da Qualidade do laboratório é o documento principal em que é explicitada qual política de qualidade laboratorial é seguida e como esta é localmente implantada, de acordo com a Figura 1.

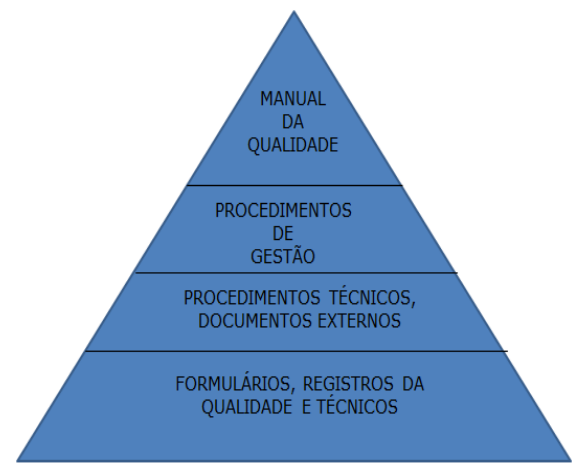

Figura 1 - Hierarquia de documentos preconizada pela Norma ABNT NBR ISO/IEC 17025:2005.

O Laboratório de Gravimetria do Observatório Nacional (LabGrav/ON, Figura 2) executa ensaios e calibrações gravimétricas para atender as necessidades de pesquisa e ensino tanto do Observatório Nacional como de outras instituições acadêmicas em parceria. Além disso, é vez por outra solicitado a atender demandas de clientes externos ao ON, seja em geofísica de exploração, seja em metrologia de força, pressão e viscosidade. Daí a necessidade de se implantar um SGQ no LabGrav, que possibilite garantia de qualidade a todos os clientes internos e externos do laboratório.

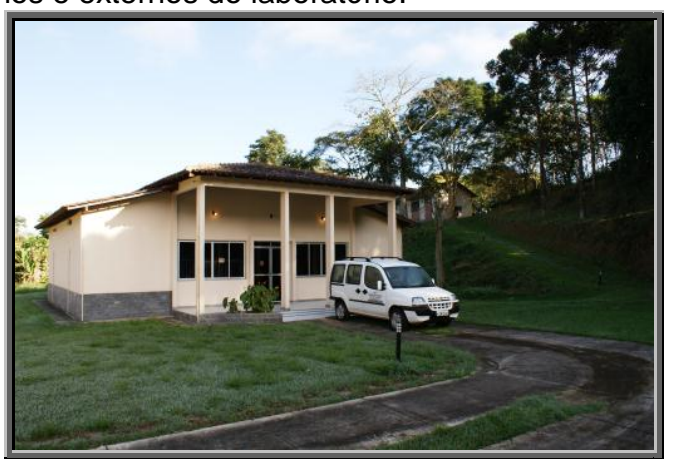

Figura 2 - O Laboratório de Gravimetria do Observatório Nacional em Vassouras (RJ). 


\section{Objetivos e relevância}

A gravimetria terrestre tem sido pesquisada no Observatório Nacional desde meados do século XIX, quando um pêndulo de Foucault foi montado para estudar a rotação terrestre na latitude do Rio de Janeiro (Oliveira, 1856, 1851). Desde então, uma característica marcante das atividades experimentais no ON referentes a esse método geofísico, tem sido a de prover o País de redes de estações gravimétricas de referência (Gama, 1973, 1972, 1971; Escobar, 1987; Sousa \& Moreira, 1994; Subiza Piña \& Sousa, 2001), o estabelecimento de linhas de calibração gravimétrica (Gama, 1968; Escobar, 1996; Sousa \& Santos, 2010) e mapas modelo de anomalias da gravidade. Ao longo do tempo, os responsáveis pela realização dessas atividades experimentais sempre procuraram seguir a melhor rotina científica disponível á época ("notório saber"), pautada pelas limitações tecnológicas e logísticas institucionais, obviamente. Entretanto, desde a aquisição de dois gravímetros absolutos de queda livre na década de 2000 (Figura 3), destaca-se a questão de formalizar a competência institucional por meio da adoção de critérios de acreditação laboratorial e de reconhecimento mundialmente aceitos. Desta forma, assegura-se que as medições gravimétricas relativas e absolutas produzidas pela equipe do laboratório e utilizadas em dissertações, teses e em trabalhos de pesquisa científica, apresentam as melhores precisões e exatidões. Os laboratórios metrológicos que demandam $\mathrm{O} \mathrm{ON}$ ao empregar a gravidade na fórmula constitutiva de seus padrões de pressão, força e viscosidade também se beneficiam, dada a crescente necessidade de demonstrar a rastreabilidade metrológica de produtos, manufaturas e serviços brasileiros, notadamente para exportação. A necessidade de acreditação nesses casos é imperiosa, pois a ausência de rastreabilidade leva a imposição de barreiras não comerciais e prejuízos ao País. As empresas de prospecção mineral e de hidrocarbonetos, muitas delas detentoras de certificação ISO 9xxx, são constrangidas a estabelecer parcerias com laboratórios científicos acreditados via a adoção da Norma 17025.

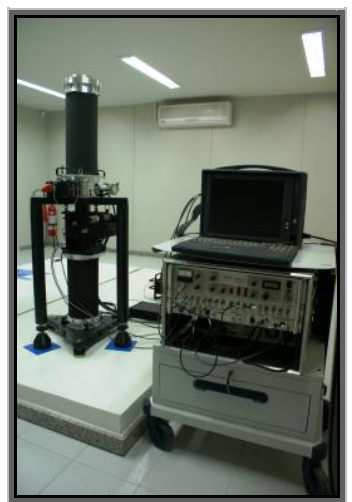

FG-5 \#223

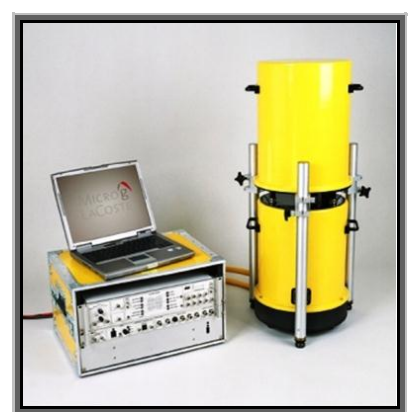

A-10 \#011
Figura 3 - Gravímetros absolutos do Laboratório de Gravimetria do Observatório Nacional. Precisão (repetibilidade) e exatidão de 0,002 mGal (FG-5) e de 0,01 mGal (A-10), Micro-g LaCoste (2006a, 2006b). Padrões primários únicos da grandeza gravidade na América do Sul.
A adoção de um SGQ no Laboratório de Gravimetria do ON baseado na Norma 17025:2005 permitirá sua acreditação e integração às Redes Brasileiras de Laboratórios de Calibração (RBC) e à de Laboratórios de Ensaios (RBLE), ambas coordenadas pelo Instituto Nacional de Metrologia, Qualidade e Tecnologia Inmetro. Em todo o mundo, vários laboratórios científicos de geofísica e geodésia física que lidam com gravidade vêm realizando esforços semelhantes àqueles ora em curso no LabGrav/ON, e.g., Slaboch, Lecher \& Pizur (2003).

\section{Metodologia}

Reconhecida a importância da implantação do SGQ do Laboratório de Gravimetria do Observatório Nacional, toda a sua equipe participou de cursos oferecidos pela Sociedade Brasileira de Metrologia (SBM) e pela Rede de Tecnologia \& Inovação do Rio de Janeiro (Redetec) sobre a Norma 17025, a avaliação e o tratamento de não conformidades, a avaliação de incertezas e a formação de auditores internos. A seguir, realizou-se um diagnóstico da situação do laboratório quanto a elaboração e revisão de todos os documentos necessários para o SGQ de acordo com a norma.

O processo de implantação do SGQ foi iniciado pela elaboração do Manual da Qualidade, que é o documento base utilizado como instrumento gerencial e onde são apresentadas as políticas para os requisitos gerenciais e técnicos. É muito importante ressaltar que implantar um sistema de gestão de qualidade não compreende apenas a elaboração dos diversos documentos que atendam as exigências da norma. A etapa mais difícil e importante é a de assegurar que esses documentos sejam seguidos rigorosamente por toda a equipe do laboratório, assimilando-se uma cultura de qualidade pouco enfatizada em laboratórios científicos. Todos os colaboradores do laboratório precisam estar envolvidos com a política de qualidade, desde seu planejamento até o gerenciamento. Esse envolvimento é conseguido por meio de mudança de comportamento dos colaboradores, que devem ter consciência das etapas, dos objetivos e das respectivas responsabilidades no funcionamento adequado do sistema.

\footnotetext{
Resultados

Construiu-se uma Lista Mestra de Documentos contemplando o Manual da Qualidade, todos os Procedimentos de Gestão Laboratorial, todos os Procedimentos Técnicos do LabGrav/ON e seus respectivos Formulários. Atualmente, é possível gerenciar todos os documentos que fazem parte do Sistema de Gestão da Qualidade do laboratório, assegurando a conformidade dos mesmos quanto a emissão. Há uma identificação unívoca dos documentos, e épocas definidas de revisão, aprovação, distribuição, arquivamento, substituição na obsolescência e os respectivos controles.
} 
Paralelamente à obtenção dos resultados descritos acima, permanece o esforço de conscientização e motivação no sentido de todos os colaboradores do laboratório compreenderem a importância dos aspectos fundamentais para a implantação da qualidade: a padronização de procedimentos e registros, a verificação rotineira e a calibração periódica de equipamentos, a importância dos registros de todas as atividades, além de senso comum de limpeza e de organização laboratorial.

\section{Referências}

ABNT NBR ISO/IEC 17025: 2005. Requisitos gerais para a competência de laboratórios de ensaios e calibração, Associação Brasileira de Normas Técnicas, Rio de Janeiro, $31 \mathrm{pp}$.

Escobar, I.P., 1987. A Rede Gravimétrica Fundamental Brasileira, Observatório Nacional, Departamento de Geofísica, 2 vv.

Escobar, I.P., Sá, N.C.de, Dantas, J.J e Dias, F.J.S.S., 1996. Linha de Calibração Gravimétrica Observatório Nacional - Agulhas Negras, Revista Brasileira de Geofísica, 14(1): 59-67.

Gama, L.I., 1971. Valores de gravidade no nordeste e região centro-leste do Brasil, Relatório Interno n-02 ONMEC, $45 \mathrm{pp}$

Gama, L.I., 1972. Valores de gravidade no centro e sul do Brasil, Relatório Interno no 4 ON-MEC, 78 pp.

Gama, L.I., 1973. Extensão da rede do nordeste, Relatório Interno nº 06 ON-MEC, 37 pp.

Gama, L.I. e Gualda, J.,1968. Base gravimétrica do Corcovado, Relatório Interno no 01 ON-MEC, 15 pp.

ISO GUM (2003) - Guia para a Incerteza de Medição, International Organization for Standardization, ABNT \& INMETRO, 3를 Edição Brasileira do ISO GUM em Língua Portuguesa, $120 \mathrm{pp}$.

Micro-g LaCoste, INC., 2006‥ The A-10 Portable Gravimeter, Lafayette (EUA), 45 pp.

Micro-g LaCoste, INC., 2006b. Absolute Gravimeter Wokshop 2006 - FG-5 Version, Lafayette (EUA), 49 pp.

Oliveira, C.B.de, 1856. Memória sobre a teoria da orientação do plano oscilatório do pêndulo simples e sua aplicação à determinação aproximada do achatamento do esferóide terrestre, Efemérides do Imperial Observatório Astronômico, Aditamento, 1: 16.

Oliveira, C.B.de, 1851. Notes dês résultats obtenues dans lês experience faites à Rio de Janeiro, sur le mouvement du pendule, pendant le mois de septembre et les premiers jours d'octobre de1851, à la latitude australe de 22ํ 50', Comptes Rendus, 33: 582.
Slaboch, V., Lecher, J. e Pizur, M., 2003. Implementation of ISO 17025:2000 in the Geodetic Metrology Laboratories and their Role in the National Metrology System, FIG Working Week, 2003, Paris,

Sousa, M.A.de e Moreira, E.M., 1994. Referring the old gravity network of the National Observatory to the IGSN 71/Absolute datum. Part I: The LC \& R 61 data set, Bulletin d'Information Bureau Gravimetrique International, 174: $30-43$.

Sousa, M.A.de e Santos, A.A.dos, 2010. Absolute gravimetry on the Agulhas Negras Calibration Line, Revista Brasileira de Geofísica, 28(2): 165-174.

Subiza Piña W.H. e Sousa M.A.de, 2001. O estado da base de dados gravimétricos do Observatório Nacional (BDG-ON), situação em junho de 2001, Revista Brasileira de Geofísica, 19(3): 325-328.

VIM (2012) - Vocabulário Internacional de Metrologia Conceitos Fundamentais e Gerais e Termos Associados, Instituto Nacional de Metrologia, Qualidade e Tecnologia, Rio de Janeiro, $1^{\text {a }}$ Edição Luso-Brasileira, 94 pp. 